\title{
THE GOES-R GEOSTATIONARY LIGHTNING MAPPER (GLM)
}

\author{
Steven J. Goodman ${ }^{1}$, Richard J. Blakeslee ${ }^{2}$, William J. Koshak ${ }^{2}$, Douglas Mach ${ }^{3}$ \\ 1. NOAA/NESDIS GOES-R Program Office, NASA GSFC, Greenbelt, MD 20771, USA, \\ e-mail steve.goodman@noaa.gov \\ 2. NASA George C. Marshall Space Flight Center/NSSTC, Huntsville, AL 35805, USA \\ 3. UA Huntsville/NSSTC, Huntsville, AL 35805, USA
}

\begin{abstract}
The Geostationary Operational Environmental Satellite (GOES-R) is the next series to follow the existing GOES system currently operating over the Western Hemisphere. Superior spacecraft and instrument technology will support expanded detection of environmental phenomena, resulting in more timely and accurate forecasts and warnings. Advancements over current GOES capabilities include a new capability for total lightning detection (cloud and cloud-to-ground flashes) from the Geostationary Lightning Mapper (GLM), and improved capability for the Advanced Baseline Imager (ABI). The Geostationary Lighting Mapper (GLM) will map total lightning activity (in-cloud and cloud-to-ground lighting flashes) continuously day and night with near-uniform spatial resolution of $8 \mathrm{~km}$ with a product refresh rate of less than $20 \mathrm{sec}$ over the Americas and adjacent oceanic regions. This will aid in forecasting severe storms and tornado activity, and convective weather impacts on aviation safety and efficiency among a number of potential applications. In parallel with the instrument development (a prototype and 4 flight models), a GOES-R Risk Reduction Team and Algorithm Working Group Lightning Applications Team have begun to develop the Level 2 algorithms (environmental data records), cal/val performance monitoring tools, and new applications using GLM alone, in combination with the ABI, merged with ground-based sensors, and decision aids augmented by numerical weather prediction model forecasts. Proxy total lightning data from the NASA Lightning Imaging Sensor on the Tropical Rainfall Measuring Mission (TRMM) satellite and regional test beds are being used to develop the pre-launch algorithms and applications, and also improve our knowledge of thunderstorm initiation and evolution. An international field campaign planned for 2011-2012 will produce concurrent observations from a VHF lightning mapping array, Meteosat multi-band imagery, Tropical Rainfall Measuring Mission (TRMM) Lightning Imaging Sensor (LIS) overpasses, and related ground and in-situ lightning and meteorological measurements in the vicinity of Sao Paulo. These data will provide a new comprehensive proxy data set for algorithm and application development.
\end{abstract}

\footnotetext{
* Correspondence to:

Steve Goodman,NOAA/NESDIS GOES-R Program Office, NASA GSFC, Greenbelt, MD 20771, USA, Brazil. Email: steve.goodman@noaa.gov
} 